\title{
6. Transparency and Development
}

\section{Karolina Gombert}

"In February in Riga, close to Calang, we had a case of measles in a little girl. Immediately, all epidemiologists of Banda Aceh came in because they were afraid of a propagation of measles among displaced people, but the little girl recovered very fast. We then realised that this was not a normal case of measles, and discovered that the girl had received the samevaccinethree times, from three different organisations. The measles symptoms were a result of the three vaccines she received” (El Pais, “Demasiado Dinero en Banda Aceh”, April 13, 2005, p. A2).

The expression "unprecedent opulence" suits the world we live in today, and yet, at the same time, "remarkable deprivation, destitution and oppression" prevail (Sen, 2000, p. xi). While one part of the earth procures money to rescue the banks in times of the global financial crisis, the other part of the planet does not even have the means to buy food. While living conditions in the affected regions after the explosions in Fukushima are close to inhuman, England celebrates the century's wedding. While people in Libya or Egypt risk their lives in the fight for democracy and human rights, the western 'culture of fear' dedicates primary attention to searching for the causative organism of the EHEC bacterium (Furedi, 2002, Culture of Fear). Development is meant to overcome such gaps between rich and poor. However, poverty, hunger and disease remain widespread (Thomas, 2001, p. 644). In this sense, the above anecdote is only one among many which exemplifies how ineffective, uncoordinated and exacerbating the practices of development aid can be. Since the so called 'charity industry' emerged after 1945 the progress of reducing poverty has been limited (Polman, 2005, Die Mitleidsindustrie). Today, one billion people in the world are chronically undernourished and two billion grapple with micronutritient malnutrition. At current rates of progress, extraordinary efforts would be required to achieve the MDG targets (Wolfensohn, 2004, pp. 7-8). This actuality stimulates a world wide debate on the effectiveness of development aid. Within this dispute, increasingly the term 'transparency' appears (Bauhr, Grimes \& Harring, 2010, p. 2). Today, many organisations in the development sector stress a link from transparency to "improved accountability, increased aid effectiveness and better value for money" (Beech, 2011, “Aid Transparency: The future of Aid is changing"). In particular, the Aid Transparency Movement, which emerged with the High Level Forum on Harmonization in 2003, is meant to improve the effectiveness of official aid. As this Movement and the first 'Open Data for Development' conference held in Amsterdam in May 2011 convey, the issue of 
transparency for development opens up a new sphere for critical thought on alternative approaches to development aid and on the conception of development as such. The development sector currently witnesses a momentum prone to change of aid practices triggered by the "new global standard" of what they call 'aid transparency' (ibid.). Aid Transparency is the presumed key to achieve aid effectiveness and correspondingly better development results. Moreover, some development workers suggest that aid transparency could revolutionize development in the sense of dissociating any negative perception of development and endow the concept with a positive connotation instead. Against this background, this article poses the question, does aid transparency really make aid more effective and revolutionize development?

\section{Aid Transparency}

Without transparency, discrepancies between aid received and aid spent are hard to measure and corruption or simply waste is more difficult to track and eliminate (Moon\&Williamson, p. 3). Yet, aid transparency does not by itself generate better budget transparency, ${ }^{41}$ accountability and effectiveness. Correspondingly, solely making aid flows from donor to recipient countries transparent is not sufficient. Instead, aid information needs to be provided in a way that is compatible with recipients' planning, budgeting and accounting processes as well (ibid.). Therefore, recently researchers focus more on transparency within recipient countries (Lindstedt \& Naurin, p. 302; Wood). Poor information on aid namely means that recipient governments have to conduct budgetary decisions based on partial or inaccurate information.

What is more, in order to employ aid transparency most efficiently, according to some researchers, transparency should actively engage the public in recipient as well as donor countries beyond being 'merely' a "basic right to know" (Stiglitz, 1999, p. 2). In this regard, in the current debate on aid effectiveness, aid transparency not only needs to encourage the publication of results, detailed program and project information but especially the active inclusion of recipients. Moon and Williamson employ this supposedly two-sided and balanced approach in their definition of the term. According to them, aid transparency is the "comprehensive availability and accessibility of aid flow information in a timely, systematic and comparable manner that allows public participation in government accountability" (p. 2).

41 Defined as "Full Disclosure of all relevant government fiscal information in a timely and systematic manner that allows public participation in government accountability" (Moon \& Williamson, p. 2). 


\section{A Social Movement}

The last years have seen an expansion of aid transparency organizations, which is often called the Aid Transparency Movement. Foremost, the names 'Aidinfo',42 'Worldvision'43 and 'PublishWhatYouFund'44 appear. It is their common aim "to bring together donors, partner countries and civil society to enhance aid effectiveness through transparency." 45 Thus, these organizations promote the central importance of aid transparency within international discussions on aid effectiveness and freedom of information. According to the anthropologist Arturo Escobar, a social movement is a source of alternatives, hopes and theories of how the world can be made differently (Ghmire, 2005, p. 1). The sociologist Touraine, on the contrary, separates from 'romanticizing' social movements and believes that they are permanently at the heart of social life (ibid., p. 2). The sociologist Rucht, however, sees value in combining both defintions. In his view, a social movement exists to the extent that two qualities are copresent. In structural terms, social movements are networks of groups and/or organisations. In regard to their aims, they are attempts to fundamentally change society including power structures and basic values or resist such changes (ibid.). In this sense, the emerging Aid Transparency Movement is a social movement as it is led by a network of aid transparency organisations which attempt to change society to 'a just world without poverty' by means of their common faith in aid transparency.

Already since the 1990s, the International Community had started to realize the costs they imposed on aid recipients by their many different approaches and requirements. Yet, it took until 2011 - after the International Conference on Financing for Development in Monterrey, Mexico in 2002, the Rome High Level Forum on Harmonization ${ }^{46}$ in 2005 and the High Level Forum on Aid Effectiveness in Accra in 2008 - when the International Aid Transparency Initiative (IATI) was launched. The IATI aims to "make information about aid spending easier to access, use and understand, helping those involved in Aid programmes to better track what Aid is being used for and what it is achieving." With the IATI, the international community has arrived at the stage where organisations and individuals in principal could select data appropriate to a specific group of users and

42 See www.aidinfo.org.

43 See www.worldvision.de.

44 See www.publishwhatyoufund.org.

45 See www.aidtransparency.net/faq.

46 For Rome Declaration on Harmonization see http://www.who.int/hdp/publications/1b_rome_ declaration.pdf. 
mix it up with information from other sources. Still, to date, no aid information system has been successful in collecting aid information in a way that interfaces effectively with the national budget (Moon \& Williamson, p. 3). In the Movement's search for 'basic shared values', the fundamental distinction between the theoretical 'recipient focused' and 'donor focused' domains of aid transparency might help to create a more interlaced understanding of how to perceive of aid transparency.

\section{Donor Focused and Recipient Focused}

While the donor focused domain of aid transparency helps to investigate the transparency of aid suppliers, the recipient focused domain is to facilitate analysis of how aid transparency is to approach recipient citizens. Currently, organizations such as PublishWhatYouFund focus on donors since much of the responsibility for greater transparency rests with them ("Spotlight on Aid Transparency"). They explicitly state: "Our campaign for aid transparency focuses primarily on the EU, U.S. and World Bank, as the world's largest aid donors." 47 Likewise, on the Aid Transparency Initiative website one can read "IATI is focused on donor transparency." 48 As much information on recipient governments is "simply presently not available" at first the focus on donors seems reasonable ("Aid Transparency Assessment 2010", p. 68).

However, according to some developmentalists such as Owen Barder, the results of the agenda in aid agencies pay too little attention to the power also "bottom up" information from the intended beneficiaries might have. Lately, a shift to a new focus on transparency in recipient countries becomes apparent (Lindstedt \& Naurin, p. 302; Wood). This is so because increased accountability to citizens is presumed as the key to unlocking better service delivery, improved governance and faster development (Owen Barder, 2011, "Eight Lessons from Three Years working on Transparency"). Thus, recently, many development workers assume a causal chain which looks as follows:

Transparency $\rightarrow$ Societal Accountability $\quad \rightarrow \quad$ Development

This presumed causal chain triggered by the new focus on recipients is interesting as it locates transparency as the catalyst leading to development through what is called 'societal accountability', scrutiny by citizens (Bauhr, Grimes \& Harring, p. 1). Yet, as common

47 See http://www.publishwhatyoufund.org/what-we-do/.

48 See http://www.aidtransparency.net/about/faq. 
sense suggests, this connection is not that straightforward. Since I align with some developmentalists in believing that the sector needs more research on the mobilizing function of transparency, the conception of the recipient focused domain is to explore this connection between transparency, societal accountability and development. First however, it shall becomeclear how to perceive of the relation between transparency and development.

\section{Connecting Concepts}

A theory of development wants to explain why specific regions or countries, often called development countries, stay behind with respect to their economy and politics (Griffin, 1989, pp. 1-23). The field of development studies emerged after the Second World War as the study of growth in newly decolonized nations around the globe (Thomas, p. 644). The widespread belief prevailed that third world states were economically backward and needed to be developed which required intervention in their economies and political systems (ibid., p. 646). Due to paradigmatic shifts and changing emphases in the academic field of development studies - from economy, to politics, to environment - the conception of development is contested (Maxfield, p. 475). Therefore, when considering the topic of development it is important to realize that like any other concept all conceptions of development necessarily reflect a particular set of values - so does the current emphasis on transparency in the sector. In order to explain this emphasis, the school of 'postdevelopmentalism' helps which stands in stark contrast to resolution oriented arenas of development studies (ibid.). Post-developmentalists emphasize that even though the earth has witnessed over seventy years of unprecedented official development policies and global economic growth, global polarization is increasing and the economic gap between rich and poor growing (Escobar, 2005, p. 23). The lemma of this postdevelopmentalist school might well be "development is the problem, not the solution" (Maxfield, p. 472). Therefore, to post-developmentalists such as Escobar it seems that "where one once spoke of Development [...] one is now allowed to speak a very different language: that of the 'crisis' of Development, on the one hand and new social actors and social movements on the other" (p. 20). In this sense, the Aid Transparency Movement can be said to have emerged as an alternative to post-developmentalism and some sort of remedy to the field of development studies. It can thus be understood as a countermovement to postdevelopmentalism. The Movement can even be put as enhancing postdevelopmentalism since it leads the sector into a new 'era' - that of aid transparency. Now, the debate has shifted from 'growth' to 'transparent' development - often in fact not much more than 
a buzzword (Hood \& Heald, 2005, p. 3). Therefore, in more malign parlance, one could insinuate that the sector while scared to be eliminated due to aid ineffectiveness, finds its "quasi religious significance" maintained in the concept of transparency and thus shifts from 'development aid' to 'aid transparency' (ibid., p. 3). In order to get even more insight into the connection between the concepts of development and transparency, Amartya Sen's account of development helps.

\section{Capability Approach}

As the title of the book Development as Freedom (2005) reveals, the concept of development is central to economist Amartya Sen's writings. Since freedom according to him is the key to fight inequity, he compiles a concept where freedom and respectively the capability to implement that freedom present the basis for ethical, political or economic action and thus the ultimate aim of development. Moreover, Sen states that all individuals are endowed with a certain set of capabilities, while it is a matter of realising these capabilities that will allow a person to escape from poverty and the state of 'unfreedom' (ibid., pp. 18-20). This perception of development as the capability to accomplish freedom is called the 'capability approach'. In particular, Sen distinguishes five freedoms: "political freedoms, economic facilities, social opportunities, transparency guarantees, and protective security". These freedoms are complementary to each other, remaining interrelated and inextricable. They constitute not only the means, but also the ends in development (ibid., p. 10). What interests us most here, is the role Sen ascribes to the freedom of transparency guarantees. Transparency, according to him, is the basis of trust (ibid., p. 39). In order to function well, a society needs transparency since it prevents corruption and the manipulation of finances and power. Sen's notion of transparency guarantees in relation to development gives impetus for connecting his development theory to aid transparency. As this freedom-centred understanding of economics and of the process of development takes the beneficiaries of aid into consideration, the new focus on recipients seems reasonable. According to Sen, individuals in developing countries need not to be seen as passive recipients of the benefits of development programs. Instead, since he argues that it is the mere existence of freedoms which allows people to take initiatives to pursue outcomes which they themselves value, it is possible to understand development as dependent on citizen mobilization (Barnett, 2008, p. 80). With adequate social opportunities, individuals can effectively shape their own destiny and help each other. In this regard, there is indeed a strong rationale for recognizing the positive role of free, sustainable agency and even of constructive impatience of recipient citizens as pursued in the Aid Transparency Movement through the recent focus on the mobilization 
potential of transparency. The alternative view presented in this article on the often taken for granted connection between transparency, societal accountability and development, integrates Sen's notion of transparency guarantees into the recipient focused domain. First, however, the conception of Open Data needs to be clear.

\section{Open Data}

The Berlin Declaration on Open Access to Knowledge in the Sciences and Humanities (2003) puts Open Data as an essential component of open access to information which is again often perceived as the key to aid effectiveness. It defines Open Data as 'raw data and metadata and source materials' to which right holders grant "to all users a free, irrevocable, worldwide right of access to, and a license to copy, use, distribute, transmit and display the data publicly and to make and distribute derivative works, in any digital medium for any responsible purpose, subject to proper attribution of authorship [...], as well as the right to make small numbers of printed copies for their personal use" (p. 2). In this sense, the Aid Transparency Movement's actors perceive of Open Data as an instrument to bridge the knowledge divides that exist in the world today.

"At the forefront" of the Aid Transparency Movement (Macdonald, 2010, "Transparency at the World Bank"), the World Bank Group (2010) states

"Open Data and innovative visualization such as the Mapping for Results Initiative are powerful tools for civil society organizations and citizens. These new approaches can increase government responsiveness, transform the way public services are delivered to citizens, and enhance transparency and accountability of development assistance. Open data combined with social media and new technologies have the potential to empower citizens to communicate directly with governments and service providers" ("Democratizing Development through Open Data").

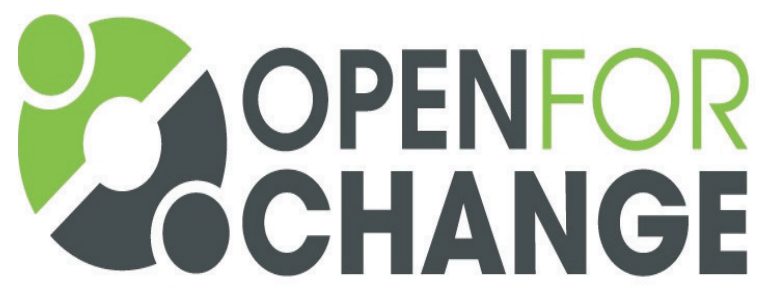

Network for Transparancy and Impact in Development

Logo 'Open Data for Development Conference',

Amsterdam, May 12-13 2011
As this quote as well as the conception of the recipient focused domain impart, recently, the transparency of data, is promoted as to cause citizen mobilization. However, which factors exactly trigger such mobilization seems to be only of preliminary concern. There is hardly any literature dealing with reasons for the presumed connection between transparency, mobilization, societal accountability and development. 


\section{Transparency's Mobilization Potential}

As Transparency International states (2011), "in development projects where beneficiaries have contributed to producing development outcomes, corruption and misappropriation of development resources has declined considerably" (p. 12) whereas "lack of public information on aid allocation hinders citizens from being partners in the prevention and identification of corruption" (p. 9). Since transparency is recently seen as enabling the complete reversibility of information exchanges between the general public and public sector organisations it is said to exhibit mobilization potential. Hence, in order to substantiate suspected abuses, to many, transparency is a key element to societal accountability actions, and therefore it is believed to function as an incentive for even greater civic engagement (Pasquier \& Villeneuve, 2007, p. 148).

In their efforts to create political will for reform, the Aid Transparency Movement actors are challenged to create enduring frames for transparency to function as a catalyst that diagnose the problems, articulate solutions and then motivate the key populations. In order to explore and facilitate in this diagnosis, it will be investigated how transparency can affect citizens. The often presumed link from transparency to societal accountability to development raises the question of whether transparency really incites indignation and empowers citizens. Or, does a flood of information rather confirm citizens' worst suspicions and give rise to resentment and resignation instead? In this sense, transparency could as well have a disempowering effect, cultivating the desire to withdraw from political matters and the public sphere. Bauhr, Grimes and Harring address these issues. In fact, they find that "increased transparency does correlate positively with measures of civic engagement" (ibid., p. 16). This means that when transparency in terms of opening up data is increased, citizens first evaluate the system they live in before they trust politicians or institutions (ibid., pp. 18-19). Nonetheless, Bauhr, Grimes and Harring point out that trust may both be an expression of resignation and indignation while only the latter may constitute a pressure for political and institutional reform (ibid., p. 19).

In this sense, on the one hand, their study provides the scientific proof that transparency holds the potential to mobilize citizens. Yet, on the other hand, the lower institutional trust in developing countries may but does not necessarily offer a promise of long-term political development when transparency is increased. Therefore, transparency should not be seen as the distinct catalyst which directly leads to societal accountability (Wood). Moreover, societal accountability should not be perceived as a static concept of citizen scrutiny. Instead, Sen's capability approach implies that societal accountability as the presumed link between transparency and development is comprised of five capabilities. This is so, because only their joint realization leads to development. Still, the questions of how to spot the 
right moment to increase transparency, and how exactly mobilization comes about, Bauhr, Grimes and Harring leave to "additional research" (ibid., p. 19). Other researchers such as the social movement theorist Bert Klandermans (1993) note that "mobilization potential is a factor at a very early stage in a movement's campaign, before a general willingness to support the movement has been activated" (p. 386). Yet, also he does not provide a clear account of when, where and how such mobilization potential is achieved. Thus, since the mobilization potential of transparency as the new focus in the Aid Transparency Movement remains unexplored, the analysis seems to arrive at an impasse here.

David Pidsley's account of the new focus on recipients as the "surprising missing link" (INT, May $10^{\text {th }}$ 2011; Wood), makes it possible to overcome the impasse by adding cultural factors to the analysis:

the focus should not be on: a. Inputs - e.g. number or status of organisations involved, amount of money put in b. Process - e.g. number of ways in which we deliver aid, number of rules and policies we have in place c. Outputs - how much we give, how many packages we send. Instead - the focus for measurement and further funding should be on the OUTCOMES. now... outcomes must be defined by the 'ultimate'/'terminal' recipient. In practice this means the organisation which is closest to the service user. With technology and crowd sourcing models it is also possible to collect service user input/feedback. And a second point... Unless the outcome is defined by ultimate/ terminal recipient, it is likely not to be met because social impact must be grounded in a life changed.

This notion of a "life changed" gives incentive to forward the reasoning based on Bauhr's, Grimes' and Harring's study by considering cultural factors. Hence, even though there is no definite equation for how transparency effects societal accountability, this is not to be a barrier since every society has to be examined distinctly (Hood \& Heald, p. 222). An investigation of corruption perception provides the means to assess how transparency can influence citizens. This is so, because since aid transparency is supposed to prevent corruption as a "major impediment to development" (Pasquier \& Villeneuve, p. 149; Lindstedt \& Naurin, p. 302), perceptions of corruption help to perceive of aid transparency as culturally dependent (Melgar, Rossi \& Smith, p. 120). When speaking of corruption, this article takes over the conception by Melgar, Rossi and Smith as "the misuse of public office with the purpose of making private gains" (ibid.). 
Against many assessments of corruption and attempted measurements of transparency which tend "to be too static - not considering the historical and cultural dimension of politics - and too superficial - just concentrating on anecdotal aspects of corruption" (Rocca, 1992, p.4O2), it follows a comparison of opinions on corruption and, correspondingly, demands for transparency in Bolivia and China. This comparison is to make clear that despite often presumed, transparency cannot mobilize citizens in the absence of what Pasquier and Villeneuve call "a profound cultural change" (p. 147).

\section{Corruption in Bolivia and China}

While China can be characterized by its political system of communism, as the largest exporteur and the second largest importeur in the world today as well as by the religions of Buddhism and Taoism, the main economic activities of the democratic Republic of Bolivia are fishing, mining, agriculture and forestery and most of the Bolivians are Roman Catholic or Protestant. It might therefore not be much of a surprise that also perceptions of corruption differ between the countries. In accordance with the new focus on recipients in the Aid Transparency Movement, voice is said to function as a deterrent of corrupt behavior (Gray-Molina, de Rada \& Yanez, 1999, p. 30). For societal accountability to occur, citizens must at first recognize corruption when it exists (ibid.). However, according to Rocca, "what is considered to be corruption in one place could be the norm elsewhere" ( $p$. 403). In order to thus markedly point to the importance of cultural factors for the recipient focused domain of aid transparency, the explicit differences between Bolivian and Chinese perceptions of corruption help.

As Gray-Molina, de Rada and Yanez detect, in Bolivia, most people believe that public hospitals together with public schools and the Catholic Church are among the least corrupt (p. 28). Instead, they define red-tape and public works related corruption as being most frequent (ibid.). In opposition, in China, the image of the average bureaucrat is that of "an honest man of modest habits whose sole objective is to serve the people" (Rocca, p. 411). Yet, according to Rocca, corruption is just "the tip of the iceberg" in communist China (ibid.). In fact, he depicts China as "a social system that assimilates corruption as one of its mechanisms" (ibid.). Even though it would go far beyond the scope of this article to douse into the specific historical contexts which have triggered the differing perceptions of corruption, according to Melgar, Rossi and Smith there are two outstanding parameters which have the most impact on corruption perception (p. 126). 
First, the parameter of "judgment of the political system" to a very large extent influences corruption perception (ibid.). This means that those who have a favourable opinion on the political system they live in, are more likely to perceive a lower level of corruption (ibid.). By empirical analysis, Melgar, Rossi and Smith conclude that "when changing from someone who believes that the state of politics in his or her country is not satisfactory to someone who has a favourable opinion, the probability [of perceiving the system as corrupt] reduces 6.9 percent" (ibid.). Thus, since Bolivians felt "being cheated" before Evo Morales became Bolivia's first democratically elected indigenous head of state in 2006 (Stiglitz, 2006, "Who Owns Bolivia?"), while in China the 'guanxi' philosophy obligates people to maintain relationships (Rocca, p. 413), it is not surprising that Bolivians tend to perceive of their political system as more corrupt than people in China.

In accordance, as a second parameter, Melgar, Rossi and Smith detect that better economic performance reduces corruption perception (p. 129). In this sense, Bolivia's macroeconomic instability and income inequality rather increase the perception of corruption while China's economic pioneering position has the opposite effect. It follows that the actual existence of corruption in a country does not necessarily direct how citizens perceive of corruption. Consequently, the concept of corruption varies widely depending on societies and people with several contrasting strands of thought and language lying behind it (ibid., p. 121). Corruption perception is thus not the reflection of an absolute situation but instead a cultural phenomenon (ibid.). Therefore, if aid transparency is to tackle corruption, the application of Open Data must be adapted to each distinct culture and applied to the indigent area - as for instance the health sector for Bolivia and the political system for China. However, at the same time, one shall take into account that in societies which undergo change, corruption may not necessarily be a negative phenomenon as it may be used by groups excluded from political power (Rocca, p. 403). Thus, the development sector needs to realize that "transparency for transparency's sake - or for punishment's sake - is ineffective and even counterproductive" (Morino, 2010, "Transparency: Compliance Driven or Culturally Dependent?"). As this comparative approach implies, only when aid transparency is applied sensitively to a country's culture, the connection between Open Data and societal accountability can be successfully established. The article now arrives at the section which presents an alternative view of aid transparency. This alternative view dissociates from the foremost deficits which many presumptions on aid transparency exhibit. Such deficits are for instance the omission of cultural factors, considering societal accountability as a static concept and the separation between 'recipient focused' and 'donor focused' domains. 


\section{An Alternative View}

In the Aid Transparency Movement, two domains of how to employ aid transparency become apparent. As indicated above, this is firstly the employment with a focus on donors, and secondly, the employment of aid transparency with a focus on recipients. The donor focused domain comprises the assumption that transparency of aid suppliers and, correspondingly, of financial aid flows leads to development. The recent presumption of transparency as exhibitting the potential to mobilize recipients, which would lead to societal accountability and ultimately to development, induces the recipient focused domain.

Within the recipient focused domain, transparency in terms of Open Data can in fact function as a catalyst leading to societal accountability - this mobilization potential being scientifically proven by Bauhr, Grimes and Harring. Yet, as the comparison between Bolivia and China implies, citizens are only being mobilized when Open Data is adapted to a country's culture. What is more, societal accountability is not to be perceived as a static concept of citizen scrutiny. Instead, since Sen's capability approach conveys that development is only achieved when citizens are able to realize their capabilities, societal accountability as the link between transparency and development is to be seen as this set of capabilities. What Sen calls transparency guarantees is only one of these capabilities (pp. 39-40). They assure people's need for openness and trust. In this sense, interestingly, transparency, in terms of Open Data, reinforces transparency, in terms of transparency guarantees within the recipient focused domain. Therefore, if one speaks of transparency as leading to societal accountability, this is only half the truth. Instead, it is transparency in form of Open Data which can lead to transparency in form of a human capability - which is among other capabilities a necessary precondition for development. Thus, the 'veil of transparency' can be said to be present throughout the whole development process within the recipient focused domain whereas many development workers attempt to endow transparency with the definite and ultimate position as the mobilizing incentive for development. However, not only citizen mobilization can lead to development. Only when the recipient focused and donor focused domains meet, development occurs. In fact, without the employment of aid transparency with a focus on donors, development would not happen. What is more, as some sort of central value, transparency holds the two domains together. In this sense, giving transparency central priority means to employ aid transparency with a focus on recipients and donors alike. Correspondingly, the more the domains merge, the larger becomes the domain of transparency and thus of development. Vice versa, the more the domain of transparency and development enlarges, the more the recipient focused and donor focused domains approximate. Thus, one could say, ideally, 
the two domains would fuse for development to reach its maximum extent. This ideal state would imply that the 'value' ascribed to transparency is completely unfolded within each of the two domains. Figure 4.1. visualizes this alternative view.

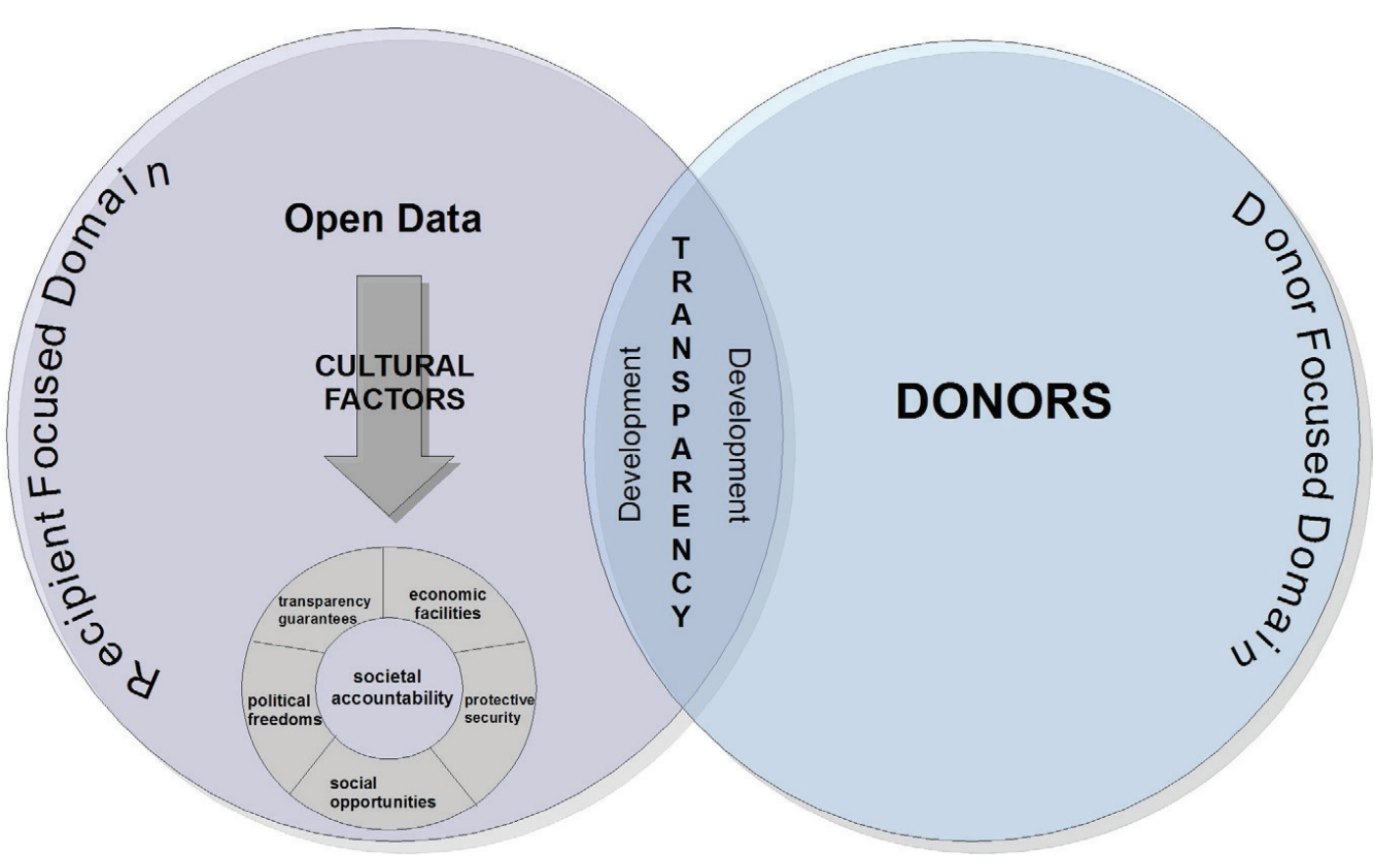

'An alternative view', source: own figure

\section{Conclusions}

As this article has shown, currently a huge building block for development aid to improve opens up. Still, the Aid Transparency Movement omits a crucial point. While the Movement is to shed light on aid processes, it leaves the actual causes of poverty, hunger and injustice in obscurity. The Movement puts corruption of aid processes as the foremost barrier to development. However, corruption is only one among other factors which hinders the development process. Thomas Pogge (2009) in this regard points out that what happens in the social world can be explained "interactionally" as well as "institutionally" (pp. 14-16). Looking at causes interactionally means to analyse actions and their effects performed by individual and collective agents. Seeing them institutionally, is to pay attention to the effects of how the world is organized and structured in terms of laws, conventions, social institutions and practices (ibid.). The actors in the Aid Transparency 
Movement must realize the current omission of two-sided and detailed cause analyses and galvanise into implementing them instead. Such omission implies that the poor are harmed by a system of global political and economic arrangements disproportionally shaped by and for wealthy western societies (Pogge, 2008, p. 23). They are not suffering because there is too little willingness to help. If the Aid Transparency Movement does not start to shed light on particular factors causing the gap between rich and poor, the Movement is not much more than a part of this western system; likely to aggravate and contribute to poverty. Moreover, as Pogge's notion of "instititutional analysis" implicates, the actors in the Aid Transparency Movement themselves need to understand all of the Movement's operations, mechanisms and influences in order to foresee whether their actions could lead to harm elsewhere (2009, p. 15). Therefore, only making aid processes transparent by concentrating on corruption as the major impediment to development is a necessary, yet, not a sufficient condition for improving aid effectiveness.

The momentum of the Aid Transparency Movement is palpable, but without greater coordination and aggregation, transparency will lead to more confusion than clarity. The dangerous tendency exists that "the moral and economic theorizing" of an 'aid transparency bubble' makes the priviledged part of the world appear even more disconnected from mass poverty (Pogge, 2008, pp.109-110). Therefore, not only the development community should push the Movement. As the Aid Transparency Movement opens up a domain for critical thought, every citizen should attach great importance to the current momentum as the one time opportunity to overcome the ambivalence of a world of unprecedent increase and overall opulence where economic poverty, social deprivation, political tyranny or cultural authoritarianism remain (Sen, p. 3). Thus, citizens in donor as well as recipient countries must take advantage of the current focus and engagement with 'inevitable' transparency in order to encourage education on the causes for the gap between rich and poor which would build on and reward aid transparency. Even though transparency is indeed hard to measure and might often appear to be vague as a concept ("Aid Transparency Assessment 2010", p.12; Lindstedt \& Naurin, p.11), the potential value attached to it,can make a difference.

In this sense, the Aid Transparency Movement itself can be said to be a part of a development process. Within this process, the Movement would turn away from transparency merely of aid flows towards transparency of the causes for the gap between rich and poor. Only if this shift in the Aid Transparency Movement occurs, aid transparency has the power to revolutionze development. Then, the concept of development would no longer be an insidious chapter but instead an intermediation sphere where citizens, institutions and development workers from recipient as well as donor countries meet. According to Sen, "development is the momentous engagement with freedom's possibility" 
(p. 298). When reflected upon, the development sector's present momentum brought about by the concept of transparency exhibits the freedom to revolutionize development towards this intermediation sphere. 


\section{Bibliography}

Barder, O. (2011). Eight Lessons from Three Years working on Transparency. Retrieved April 20, 2011 from http://www.owen.org/?s=ey+to+unlocking+better+service+delivery\%2C+imp roved+governnnce+and+faster+Development+

Barder, O. (2011). Complexity - the simple path to success in development. The Guardian, 08/02/2011.

Barnett, J. (2008). Peace and Development: Towards a New Synthesis. Journal of Peace Research, 45(1), 75-89.

Beech, A. (2011). Aid Transparency: The future of aid is changing. Retrieved April 20, 2011 from http://devpolicy.org/the-future-of-aid-is-changing/

Castells, M. (2000). The Information Age: Economy, Society and Culture. Volume 1: The Rise of the Network Society: Blackwell Publishers.

Escobar, A. (1995). Imagining a Post-Development Era? Critical Thought, Development and Social Movements. Retrieved March, 8, 2011 from http://www.unc.edu/ aescobar/text/eng/escobarg2.pdf.

Furedi, F. (2002). Culture of Fear: risk-taking and the morality of low expectation. London: Continuum.

Gray-Molina, G., Perez de Rada, E. \& Yanez, E. (1999). Transparency and Accountability in Bolivia: Does Voice Matter? Retrieved April 28, 2011, from http://www.iadb.org/res/ publications/pubfiles/pubr-381.pdf

Griffin, K. (1989). Alternative Strategies for Economic Development. Houndmills, Basingstoke, Hampshire \& London: Macmillan Academic and Professional Itd.

Harring, N., Grimes, M. \& Bauhr, M. (2010). Seeing the State. The Implications of Transparency for Societal Accountability. OoG Working Paper Series 2010: 15.

Heald, D. \& Hood, C. (2006). Transparency. The Key to Better Governance? Oxford: University Press.

Levy, R. (2003). The Village Self-government movement: Elections, Democracy, the Party, and Anticorruption - Developments in Guangdong. China Information 2003, 17, 28-65

Lindstedt, C. \& Naurin, D. (2010). Transparency is not Enough: Making Transparency Effective in Reducing Corruption. International Political Science Review, 31(3), 301-322.

MacDonald, E. (2010). Transparency at the World Bank. Retrieved May 25, 2011, from http://globaladminlaw.blogspot.com/2010/04/transparency-at-world-bank.html

Maxfield, S. (2002). "International Development". In Carlsnaes, W., Thomas, R. \& Simmons, B.A. (2002). Handbook of International Relations. London, Thousand Oaks \& New Dehli: SAGE Publications.

Melgar, N., Rossi, M. \& Smith, T.W. (2010). The Perception of Corruption. International Journal of Public Opinion Research, 22(1), 120-131. 
Moon, S. \& Williamson, T. (2010). Greater Aid Transparency: crucial for aid effectiveness.

Retrieved April 17, 2011, from http://www.odi.org.uk/resources/download/4673.pdf

Morino, M. (2010). Transparency: Compliance Driven or Culturally Dependent? Retrieved May 27, 2011 from http://www.vppartners.org/learning/chairmans-corner/transparencycompliance-driven-or-culturally-ingrained.

Pasquier, M. \& Villeneuve, J. (2007). Organizational barriers to transparency: a typology and analysis of organizational behaviour to prevent or restrict access to information. International Review of Administrative Sciences, 73(1), 148-162.

Piotrowski, S. J. \& Ryzin, G. G. van (2007). Citizen Attitudes Toward Transparency in Local Government. The American Review of Public Administration, 37(3), 306-323.

Pogge, T. (2009). Politics as Usual: What Lies Behind the Pro-Poor Rhetoric. Cambridge: Polity Press. Pogge, T. (2008). World Poverty and Human Rights. $2^{\text {nd }}$ Ed. Cambridge: Polity Press.

Polman, L.(2010).Die Mitleidsindustrie. Hinter den Kulissen internationaler Hilfsorganisationen. Frankfurt/New York: Campus Verlag.

Rocca, J. (1992). Corruption and its Shadow: An Anthropological View of Corruption in China. The China Quarterly, 130, 402-416.

Sen, A. (2000). Development as Freedom. New York: Anchor Books.

Shah, P. (2002). Transparency Guarantees in Amartya Sen's "Development as Freedom". Retrieved March, 8, 2011 from http://www.ccsindia.org/ccsindia/article/pdf/transp_ guarantees.pdf.

Stiglitz, J. E. (1999). On Liberty, the Right to Know, and Public Discourse: The Role of Transparency in Public Life. Retrieved February 10, 2011, from http://derechoasaber.org.mx/documentos/ pdfo116.pdf.

Stiglitz, J. E. (2006). Who owns Bolivia? Retrieved April 24, 2011 from http://www.projectsyndicate.org/commentary/stiglitz71/English.

Thomas, C. (2001). Poverty, development and hunger. In Baylis, J., Smith, S. \& Owens, P. (2001). The Globalization of World Politics. An introduction to international relations. Third Edition. Oxford: University Press.

Wolfensohn, J. (2004). Process in the Fight against poverty. Retrieved June 22, 2011 from http:// www.worldbank.org/progress/progress_part_1_part_2.pdf

Wood, T. (2011). The surprising missing link in the aid transparency chain: Recipients. Retrieved May 24, 2011 from http://devpolicy.org/the-surprising-missing-link-in-the-aidtransparency-chain-recipients/

(N.A.) (2011). Spotlight on Transparency. Retrieved April 17, 2011, from http://www.ode.ausaid. gov.au/publications/pdf/briefs-transparency-feb11.pdf.

(N.A.) (N.D.). International Aid Transparency Initiative (IATI). Provided by Beris Gwynne, Director, WVI Global Capitals (Geneva) and Partnership Leader, Global Accountability, World Vision International, April 29, 2011. 
(2007). Poverty, Aid and Corruption. Transparency International Policy Paper \#1/2007.

(2010). Aid Transparency Assessment 2010. Retrieved April 17, 2011, from http://siteresources. worldbank.org/CSO/Resources/Aid_Transparency_Assessment_2010.pdf

(2010). Berlin Declaration on Open Access to Knowledge in the Sciences and Humanities. Retrieved May 25, 2011 from http://oa.mpg.de/files/2010/o4/berlin_declaration.pdf 